\title{
Glioma in an AIP mutation carrier patient
}

S. Datta ${ }^{1}$, M. N. Dang ${ }^{1}$, A. Solomou ${ }^{1}$, A. Baborie ${ }^{2}$ \& M. Korbonits ${ }^{1}$ ${ }^{1}$ Centre for endocrinology William Harvey Research Institute (WHRI), Barts and the London School of Medicine and Dentistry, Queen Mary University of London (QMUL), London EC1M 6BQ, UK

${ }^{2}$ The Walton Centre for Neurology and Neurosurgery, L9 7LF, Liverpool, UK

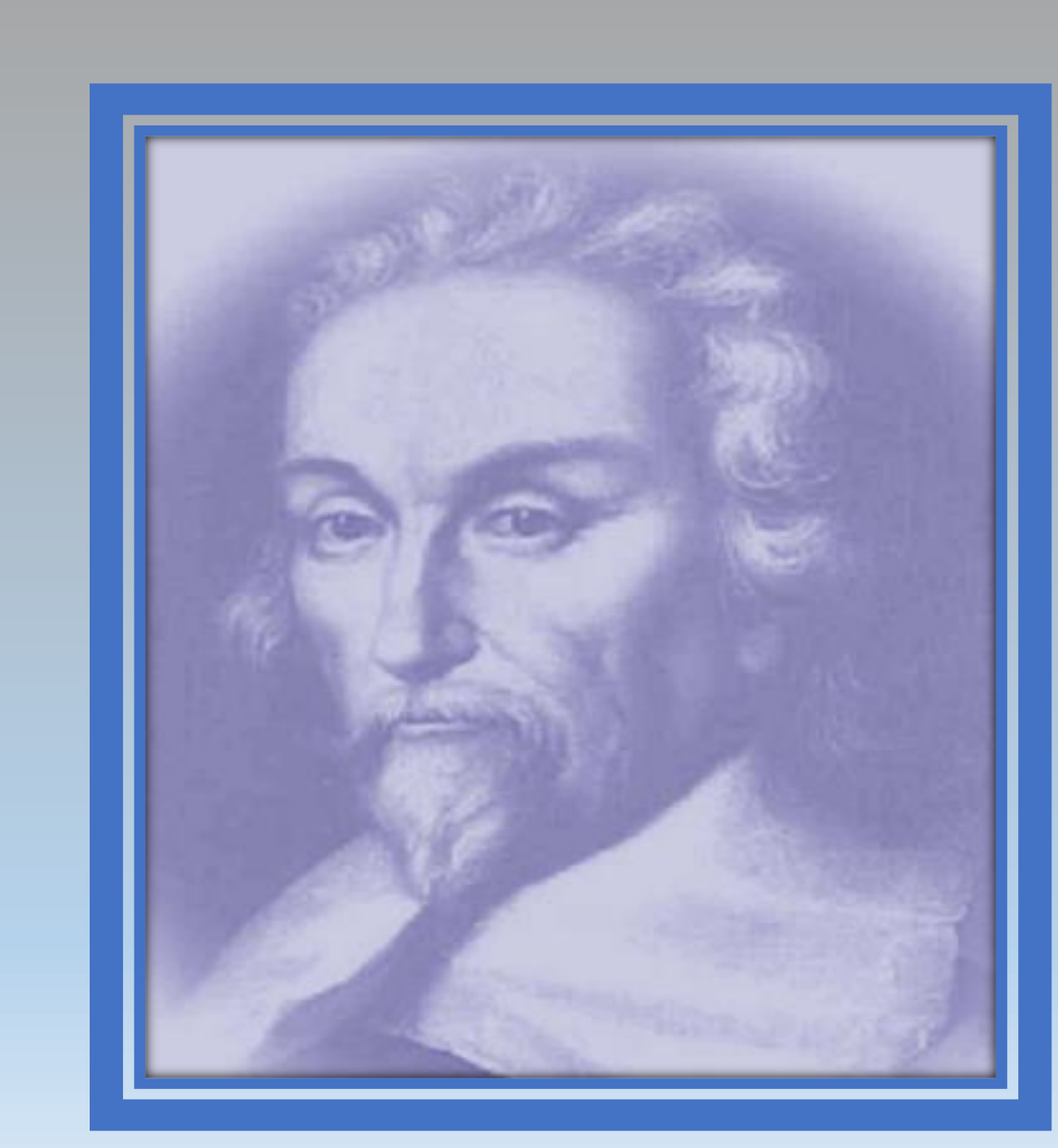

\section{INTRODUCTION}

Patients with mutations in the aryl hydrocarbon receptorinteracting protein (AIP) gene are characterised by young onset somatotroph or lactotroph macroadenomas.

AIP is believed to be a tumour suppressor gene (TSG). Loss of heterozygosity ( $(\mathrm{OH})$ has been discovered in pituitary adenoma samples from AIP mutation-positive patients and it is believed that $A I P$ LOH is required for oncogenesis to occur ${ }^{1}$.

A 53 years old male patient who was a carrier of a pathogenic AIP mutation (R304*), but was not affected by a pituitary adenoma (Figure 1), was identified with a low-grade glioma when clinical screening was first performed due to his carrier status (Figure 2). After 4 years of observational follow-up he was operated due to tumour enlargement.

Low grade gliomas are brain tumors arising from two different types of brain cells known as astrocytes and oligodendrocytes.

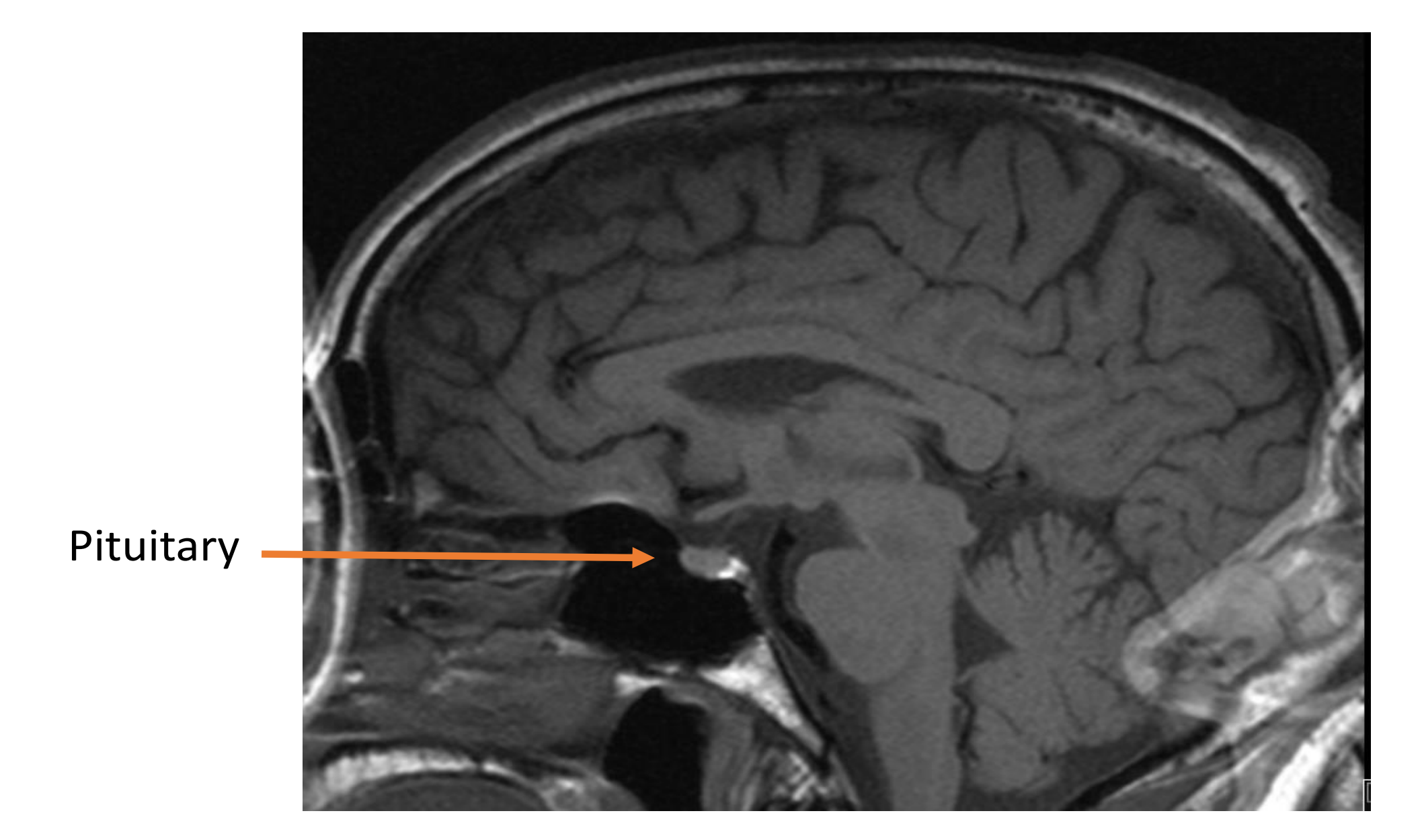

Figure 1: Sagittal MRI scan showing a normal pituitary

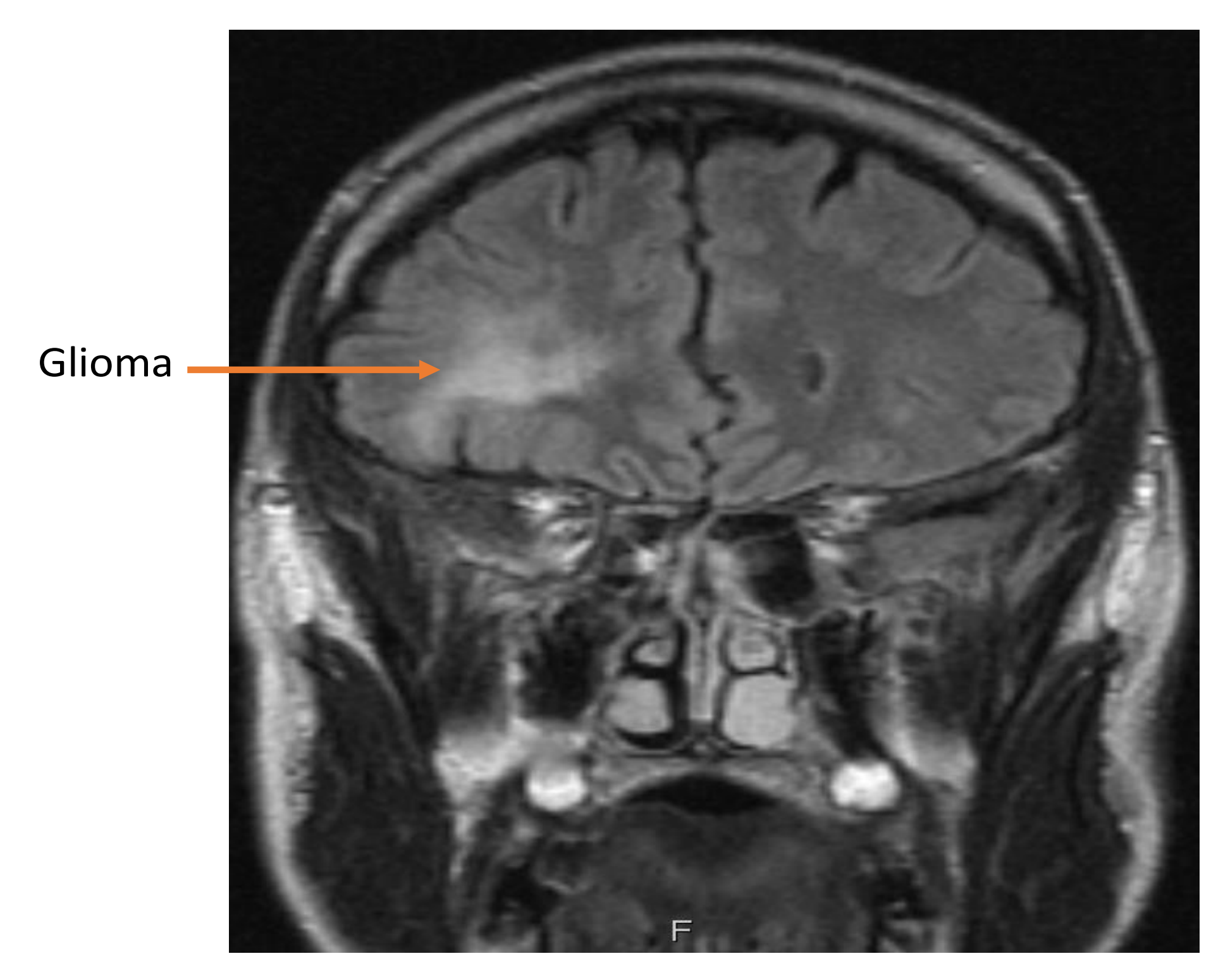

Figure 2: Coronal MRI portraying the glioma in the right hemisphere.

\section{AIMS \& OBJECTIVES}

\section{Aim:}

Validate whether AIP may play a role in this patient's low grade glioma.

\section{Objective:}

To test if the glioma sample has lost the wild-type copy of AIP gene.

\section{METHODS}

\section{DNA extraction:}

DNA was extracted from the patients blood using QIAamp DNA Blood Mini Kit.

DNA was extracted from the patient's glioma tissue, marked on H\&E slide by a neuropathologist avoiding surrounding nontumorous tissue, using a QIAamp DNA FFPE Tissue Kit.

\section{PCR:}

A PCR experiment was carried out on blood-derived and glioma-derived DNA from the patient to amplify the region (exon 6) possessing the patient's AIP mutation (R304*). The PCR product was purified using Qiagen gel extraction kit and sent off for Sanger sequencing.

\section{RESULTS}

PCR bands showing amplification from blood and tumourderived DNA (Figure 3)

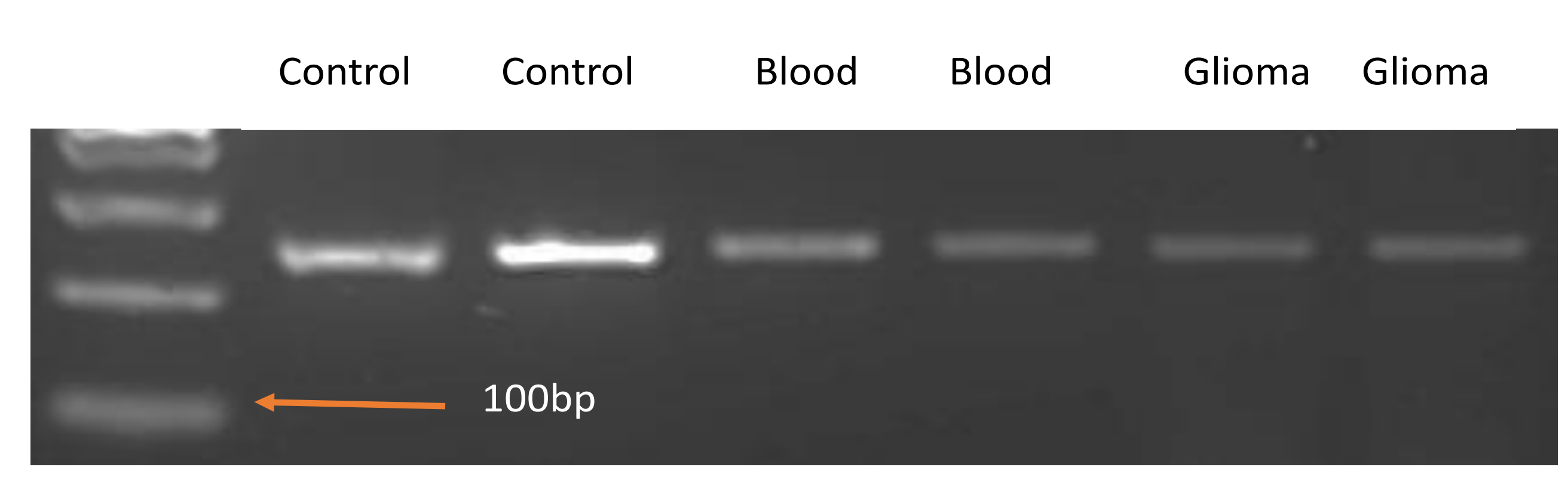

Figure 3: The agarose gel showed bands present in all of the DNA samples.

\section{Sequence analysis:}

Sequence analysis of the R304* AIP mutation of exon 6 performed in both glioma tissue $\&$ blood DNA showing a heterozygous mutation (highlighted in blue). No LOH was identified (Figure 4).

Tissue

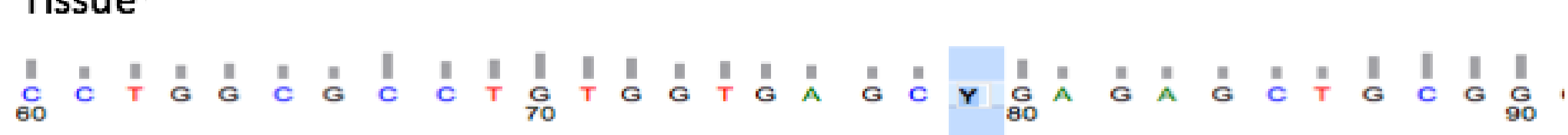

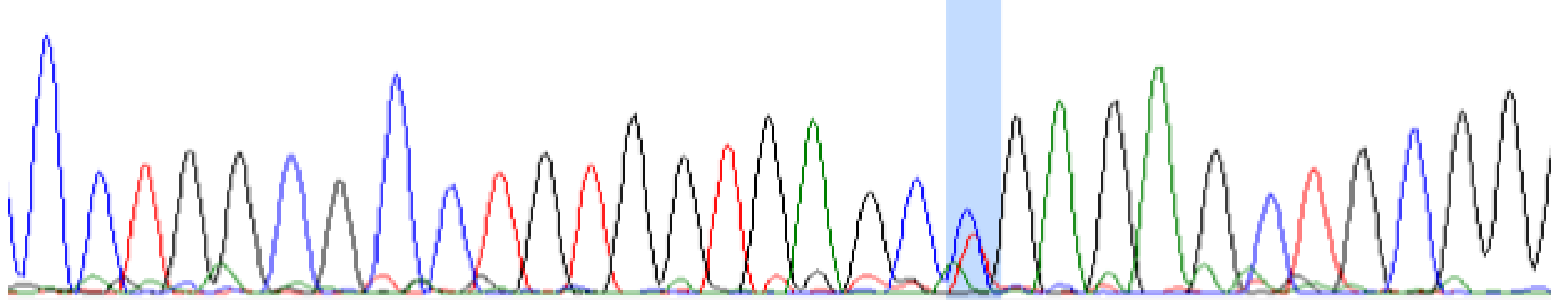

Blood
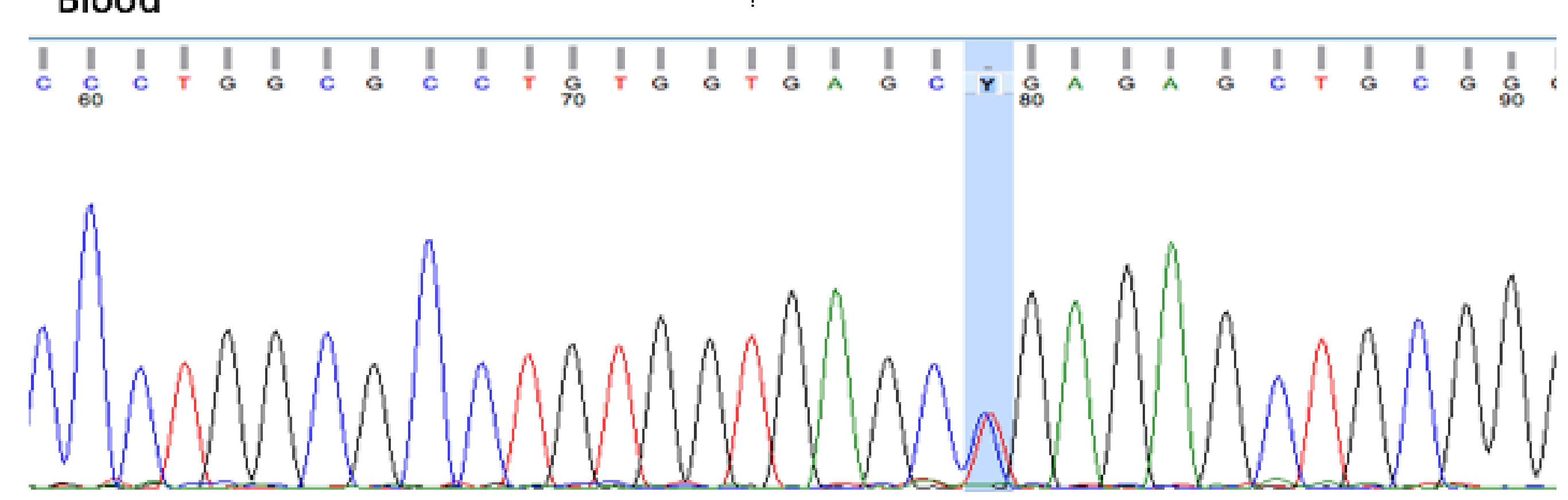

Figure 4: Sequence analysis of the R304* AIP mutation of exon 6.

\section{DISCUSSION}

The results indicate that there was no $\mathrm{LOH}$ of $A I P$ in the patient's glioma tissue. Although the most common mechanism to lose the wild-type copy of a TSG in the tumour tissue is large deletion affecting the wild-type allele, other mechanisms could also play a role, such as another somatic mutation in other parts of the gene, or silencing of the wildtype copy with epigenetic mechanism - promoter methylation or microRNAs.

We have shown previously that a meningioma in a patient with acromegaly due to an AIP mutation also did not show $\mathrm{LOH}$ in the meningioma tissue while $\mathrm{LOH}$ was present in the pituitary adenoma (1) and similar data exist for other tumours (2).

AIP mutations are known to have a low penetrance. At this point there is no genetic or molecular explanation for this low penetrance. There is a possibility that other, more general cancer development genes might play a role, as there is several data available suggesting that patients with pituitary adenomas have a higher risk of other tumours (3-5). This suggests that in families where a pituitary tumour develops, other cancer predisposing variants are also present. While this patient did not have a pituitary adenoma, his brother suffered of early-onset acromegaly, clearly being one of the carrier subjects manifesting in this family. Whether there is a link between this patients glioma and the manifestation of pituitary adenoma in the brother is unclear.

\section{CONCLUSION}

It is unlikely that the R304* AIP mutation would play a role in the development of this patient's glioma.

\section{REFERENCES}

1. Guaraldi, F., Corazzini, V., Gallia, G., Grottoli, S., Stals, K., Dalantaeva, N., Frohman, L., Korbonits, M. and Salvatori, R. (2012). Genetic analysis in a patient presenting with meningioma and familial isolated pituitary adenoma (FIPA) reveals
selective involvement of the R81X mutation of the AIP gene in the pathogenesis of selective involvement of the R81X mutation of
the pituitary tumor. Pituitary, 15(S1), pp.61-67.

2. Toledo, R., Mendonca, B., Fragoso, M., Soares, I, Almeida, M. Moraes, M., Lourenço-Jr, D., Alves, V., Bronstein, M. and Toledo, S. (2010). Isolated familial somatotropinoma: 11Q13-LOH and gene/protein expression analysis suggests a possible involvement of AIP also in non-pituitary tumorigenesis. Clinics, 65(4), pp.407-415.

3. Popovic, V., Damjanovic, S., Micic, D., Nesovic, M., Djurovic, M., Petakov, M., Obradovic, S., Zoric, S., Simic, M., Penezic, Z. \& Marinkovic, J. (1998) Increased incidence of Clinical Endocrino 4. Haley Gittleman, Quinn T. Ostrom, Paul D. Farah, Annie Ondracek, Yanwen Chen, Yingli Wolinsky, Carol Kruchko, Justin Singer, Varun R. Kshettry, Edward R. Laws, Andrew E. Sloan, Warren R. Selman, Jill S. Barnholtz-Sloan, Descriptive
epidemiology of pituitary tumors in the United States, 2004-2009, Journal of epidemiology of pituitary tumors in the United States, 2004-2009, Journal of 5. Margriet G $2014,121,3,527$

5. Margriet G.A. Sattler, André P. van Beek, Bruce H.R. Wolffenbuttel, Gerrit van
den Berg, Wim J. Sluiter, Johannes A. Langendijk, Alphons C.M. van den Bergh, The den Berg, Wim J. Sluiter, Johannes A. Langendijk, Alphons C.M. van den Bergh, The
incidence of second tumours and mortality in pituitary adenoma patients treated with postoperative radiotherapy versus surgery alone, Radiotherapy and Oncology, with postoperative

Correspondence: m.korbonits@qmul.ac.uk 